NEWS, VIEWS, AND COMMENTS

\title{
Solvent Exposure and Parkinson's Disease: Co-Twin Control Study/ Twin Research Reports / Human Interest Stories
}

\author{
Nancy L. Segal \\ Department of Psychology, California State University, USA
}

Naturally occurring co-twin control designs can assess associations between environmental hazards and disease risk because the genotypes of monozygous twins are the same. The first population-based study to explore links between solvent exposure and Parkinson's disease used 49 discordant monozygous twin pairs, as well as a comparison group of
50 discordant dizygous twin pairs. The methods, findings and implications from this important study are reviewed. Reviews of twin research concerning gender identity disorder, prenatal development and the VATER syndrome follow. A sampling of engaging and informative twin-related news items is also presented.

\section{Solvent Exposure and Parkinson's Disease: A Co-Twin Control Study}

The possible health risks posed by solvents and other chemical substances in our occupational and recreational environments have concerned medical professionals and the public. Parkinson's disease is a progressive, degenerative disorder of the nervous system affecting movement and other body functions (Mayo Clinic, 2012). It has attracted considerable interest, given hypothesized associations with exposure to various hazardous environmental materials. Substantiating this view is that past twin studies of Parkinson's disease have failed to find compelling evidence of genetic effects when the illness was diagnosed after age 50 (Tanner et al., 1999). However, when at least one twin's age at onset was 50 or younger, then genetic factors appeared to play a role.

Disentangling the risk of illness from genetic factors and environmental exposure is best accomplished by studying the life histories of monozygous (MZ) co-twins discordant for relevant diseases, because the genotypes of $\mathrm{MZ}$ twins are the same.

An interdisciplinary team of investigators from the United States and Canada conducted the first populationbased study of possible associations between solvent expo- sure and Parkinson's disease (Goldman et al, 2011). Rather than rely on case-control methods in which genetic and environmental factors could not be fully controlled, the researchers gained access to $\mathrm{MZ}$ twins discordant for the disease. A comparison sample of discordant dizygous (DZ) twins was also available for study.

The sample included 198 disease-discordant twin pairs (85 MZ, $110 \mathrm{DZ}$, and 3 of undetermined zygosity). All twins were male, having been identified from the National Academy of Sciences/National Research Council World War II Veteran Twin Registry. Affected twins and their twin brothers were evaluated in person by a specialist in movement disorders; the evaluation included a videotaped neurological examination. Twins' medical records were also inspected. Based on all available information, the diagnosis of Parkinson's disease was made by two separate neurologists.

Twins also completed detailed questionnaires to determine their lifetime exposure to six different solvents, namely

ADDRESS FOR CORRESPONDENCE: Nancy L. Segal, Department of Psychology, California State University, Fullerton, CA 92834, USA. E-mail: nsegal@exchange.fullerton.edu 
$n$-hexane, xylene, toluene, carbon tetrachloride $\left(\mathrm{CCI}_{4}\right)$, trichloroethylene (TCE), and percholomethylene (PERC). However, this information was gathered indirectly because most individuals are unaware of the specific chemical substances in their environments. This task was accomplished by administering a detailed occupational exposure assessment that had been developed previously for cancer research. The nature and degree of solvent exposure was then inferred for each job, based on the twins' occupational histories. Twins additionally indicated their histories of smoking and head injuries. Proxy informants were used when twins were unable to complete the assessment battery.

Across the entire sample, the proportion of pairs with at least one exposed twin was greatest for toluene (27\%) and lowest for PERC (6\%). Individuals holding jobs as cabinet makers, artists, mechanics, electricians, and carpenters were those most likely to have been exposed to toluene. However, in $48 \%$ of the pairs, either one or both twins had been exposed to at least one or more of the six specified solvents. Risk for Parkinson's disease was highest for individuals exposed to the combination of TCE and PERC. However, risk was modestly (albeit, not significantly) elevated if there was exposure to any of the six solvents, or any of the four excluding PERC and TCE. Solvent exposure was not associated with the age at diagnosis of Parkinson's disease, but the investigators noted that they had little statistical power to assess this relationship.

This important study raises key concerns for the general public. For example, TCE, PERC, and $\mathrm{CCI}_{4}$ have been used widely for many years. TCE is used in dry cleaning and degreasing and has been an additive in many household products such as typewriter correction fluid and spot removers (The use of computers for word processing has probably reduced the use of typewriter correction fluid!). TCE has been detected in air, soil, and human breast milk. Of course, replication of the study using other samples will be the next step. The retrospective and indirect nature of the study also mandates that prospective and direct analyses be conducted. The investigators noted these limitations of their study.

An unanswered question that the investigators should have addressed was whether the $M Z$ twin pairs showed greater concordance for solvent exposure and Parkinson's disease risk than the $\mathrm{DZ}$ twin pairs. These data would have added to the literature on this topic, despite the small sample size. It is also unclear why the analyses combined the MZ and DZ twin pairs - the introductory section indicates that because twins are 'genetically very similar or identical, and share many demographic and lifestyle factors, discordant twin-pair designs are more resistant to confounding factors than typical case-control study designs' (pp. 1-2). That is true, of course, but only for MZ twins. DZ twins may differ considerably with reference to their genetically based disease predispositions and lifestyle choices that might eventuate in different job choices and unequal solvent exposure. Disease discordance in $\mathrm{MZ}$ and $\mathrm{DZ}$ twins might, therefore, have different underlying factors. It is possible that an unknown proportion of discordant DZ twin pairs resulted from the co-twins' different genetic predispositions and had little to do with their different degrees of solvent exposure. Nevertheless, this study deserves to be read in full and the results taken seriously. It is a key step toward understanding who is at risk for Parkinson's disease, and why. Also see a comment by Segal (2012) and a reply by the authors.

\section{Research Reviews \\ Gender Identity in Twins}

The reason for $\mathrm{MZ}$ twin discordance for gender identity disorder (GID) is a timely topic. A recent review of case reports documenting GID in one or both MZ and DZ cotwins has been undertaken by researchers in Belgium and Canada (Heylens et al., 2012). The 23 MZ, 21 same-sex $\mathrm{DZ}$, and $7 \mathrm{DZ}$ opposite-sex twin pairs were identified in the published literature. However, among them were 25 young twin pairs available from Toronto's Gender Identity Service at the Centre for Addiction and Mental Health.

A significant difference in GID concordance was found between the MZ (39.1\%) and same-sex DZ (0\%) twin pairs $(p<.005)$. Furthermore, none of the opposite sex-twin pairs was concordant. These findings demonstrate that genetic factors contribute to individual differences in GID. This paper includes an insightful discussion of GID and excerpts from the life histories of selected twin sets.

\section{Cerebral Development in Twin Transfusion Syndrome}

Twin-to-twin transfusion syndrome (TTTS) is a widely recognized problem in MZ twin pregnancies. It estimated that the co-twins in 10-20\% of monochorionic pregnancies are affected by an imbalance in circulation between the donor (depletion) and recipient (excess). A recent retrospective study compared the brain images of 33 twin pairs that included 18 healthy twins (Tarui et al., 2012). The aim was to compare the frequency of brain abnormalities and quantitative biometrical parameters between the healthy and affected infants, and with healthy controls.

Results revealed measurable differences in cerebral and/or cerebellar brain growth in both the donor and recipient twins. The frequency of abnormalities was higher than previously reported (11/33, or 33\%). Ventriculomegaly (enlarged ventricles) was the most common condition noted among both the donor and recipient twins, occurring in $7 / 11$, or $63 \%$ of the cases. Interestingly, healthy twins who experienced TTTS showed reductions in various brain measurements (e.g., cerebral mantle thickness and transverse cerebellar diameter). It was concluded that the normalappearing brains of healthy TTTS twins may not reveal the subtle abnormalities that can be detected with sophisticated imaging techniques. The findings also explain the increased rate of learning problems observed among twin survivors of TTTS. 


\section{VATER Syndrome}

In January 2012, I received a note from a mother of teenage MZ twin girls, who wrote, 'The thing that may make them of particular interest is that one of the girls is completely normal, and the other was born with a cluster of birth defects known as VATER (or VATERL) syndrome ... We were told that the only possible cause for these birth defects (perhaps because it is unknown) is some sort of interruption in the pregnancy.'

VATER(L) denotes possible abnormalities in the vertebrae, anus, trachea, esophagus, renal (kidneys), and limbs. Affected children do not necessarily have defects in all areas, but in subgroups. There is no known cause of VATER syndrome, and most cases appear to occur sporadically. The features of VATER syndrome are, however, more frequent among twins (WebMD, 2012), presumably $\mathrm{MZ}$ twins, than non-twins, due to the vagaries of zygotic division.

I spoke with the mother at length about her twin daughters. Her pregnancy was unremarkable with the exception of some bleeding at five-and-a-half months. Some time after that, she was diagnosed with placenta previa (a pregnancy complication in which the placenta covers all or part of the opening to the cervix) and urged to return home to the United States from western Africa, where she was visiting at the time. She experienced another small bleed at 35 weeks before delivering the twins by planned Caesarean section three weeks early. The twins were monozygous and dichorionic.

The twins are currently both healthy, although the affected twin has undergone an extensive series of surgeries, and more are expected. The twins are good friends and support one another fully. Meanwhile, the origins of VATER syndrome continue to elude physicians and other specialists, although it is suspected that temporary blood flow interruption during the pregnancy may be responsible.

\section{Human Interest Stories Basketball Careers}

The identical 6-foot-10-inch Wear twins, David and Travis, have attracted a great deal of attention following their relocation to UCLA from the University of North Carolina to play basketball for the Bruins (Holmes, 2011). Their performances have been better than anticipated, given that they were sidelined for the first year and suffered from a series of health problems. David averages 8.0 points per game, while Travis averages 10.6. The twins' skills were closely matched in high school when David's national ranking was 26 and Travis's was 27. Still, their coaches say that the twins play differently — David is better at rebounds and outside shooting, while Travis has more post moves. When the twins discuss their habits and personalities, they more often cite qualitative as opposed to quantitative differences between them. For example, David is slightly more serious and Travis is slightly more organized.

In December 2011, Travis was rushed to a hospital for treatment of a foot infection, leaving David to play alone for the first time. He did not play well, scoring 7 points and missing 6 of 8 shots. When Travis was released from the hospital, he attended the next game and sat on the sideline, but this time David played well - his best game of the season. The twins' father explained this result with reference to the strong psychological connection between his sons. Other identical twins have also achieved elite status in the world of sports, for example, Bob and Mike Bryan (tennis), Bia and Branca Feres (synchronized swimming), and Steven and Phil Mahre (skiing). During my interviews with some sports-minded twins, twins have explained their matched talents with reference to their matched abilities, constant practice, and mutual support (Segal, 2000). Further study of such twin pairs may help coaches identify the most important ingredients of superb athletic skill.

\section{Mysterious Double Death}

Identical twins, Joan and Patricia Miller, born in 1939, began their careers as singers and entertainers. They appeared briefly on the 1950s television show, 'The Hoffman Hayride', and were photographed with Bing Crosby. Neither twin married, and in 1976 they purchased a large home together in South Lake Tahoe, California. Joan was a senior accounting clerk in the payroll department of the local school district until 1984. Her sister was employed by the El Dorado County's social services. The twins led a reclusive existence, withdrawing from neighbors and never returning telephone calls.

The twins became newsworthy once again in early March, 2012, when police discovered both twins dead (Associated Press, 2012). The police made regular checks on the twins at the request of a neighbor and, on one of these occasions, one twin was found dead in a downstairs bedroom and the other twin was found in a hallway nearby. The cause of death is unknown, but speculation suggests that one twin passed away and the other twin killed herself because living alone would have been unbearable. The possibility that one twin had been ill was raised when an ambulance was seen outside their home a year ago. However, most residents in the community had never heard of the twins.

Twin research has indicated genetic effects on longevity (Hjelmborg, et al., 2006) and on suicidal behavior (Segal, 2009). In the case of the Miller twins, it may be some time before the facts surrounding their mysterious deaths are known.

\section{Dizygotic Twins Reunited}

Emilie Falk and Lin Backman grew up just 25 miles from one another in southern Sweden. Following their reunion at age 28 , DNA tests confirmed with greater than $99 \%$ probability that they were full siblings. The twins are Indonesian. The 
details of their adult meeting are extraordinary, traceable to the casual remarks of a taxi driver (Huffington Post, 2012).

There was no mention of a twin sister when the Backman family adopted Lin from the orphanage. However, a taxi driver asked her parents the whereabouts of 'the sister'. At this point, the parents wrote down the twins' Indonesian names and were able to contact the other family. However, the two sets of parents decided that their daughters were different enough and were probably unrelated. Then, when Falk married two years ago, she became interested in her family history and learned she might have a twin sister. She found her sister on Facebook.

A considerable body of research shows that reared-apart fraternal twins are less similar behaviorally than rearedapart identical twins. Nevertheless, individual pairs can show some remarkable resemblances. Falk and Backman had both trained as teachers, had married on the same day, and had danced to the same song at their weddings. Their body builds differ, in that Backman is taller and thinner and has longer legs. Most importantly, the twins are happy to have found one another and plan to visit Indonesia to learn more about who they are.

\section{Take Two! A Celebration of Twins}

A children's book of poems about twins will be released later this month (I have not seen it). Take Two!, written by poets J. Patrick Lewis and Jane Yolen, may be more appreciated by adult twins, parents of twins - and maybe twin researchers - than by the young twins for whom it is intended (Paul, 2012). The poems are organized into four categories, the first titled, 'Twins Waiting in the Womb'. The book also includes various 'twin facts' and references to wellknown twin pairs such as the conjoined twins, Chang and Eng. The lead author is not just the current children's poet laureate - he is also a twin.

\section{References}

Associated Press (2012, March 7). Reclusive twins, 73, leave behind mystery in death. Retrieved from http://news.yahoo.com/reclusive-twins-73-leave-behindmystery-death-083220870.html
Goldman, S. M., Quinlan, P. J., Ross, W., Marras, C., Meng, C., Bhudhikanok, G. S., Comyns, K., Korell, M., Chade, A. R., Kasten, M., Preistley, B., Chou, K. L., Fernandez, H. H., Cambi, F., Langston, J. W., \& Tanner, C. M. (2011). Solvent exposure and Parkinson disease risk in twins. Annals of Neurology. Advance online publication. doi: 10.1002/ana.22629

Heylens, G., De Cuypere, G., Zucker, K. J., Schelfaut, C., Elaut, E., Vanden Bosche, H., De Baere, E., \& T'sjoen, G. (2012). Gender identity disorder: A review of the case report literature. Journal of Sexual Medicine, 9, 751-757.

Hjelmborg, J. v. B., Iachine, I., Skytthe, A., Vaupel, J. W., McGue, M., Koskenvuo, M., Kaprio, J., Pedersen, N. L., \& Christensen, K. (2006). Genetic influence on human lifespan and longevity. Human Genetics, 119, 312-321.

Holmes, B. (2011, December 20). Step-up brothers. In Los Angeles Times, pp. C1, C5.

Huffington Post (2012, 9 March) Indonesian twins, Lin Backman and Emilie Falk, separated at birth, reunite in Sweden. Retrieved from http://www.huffingtonpost.com/ 2012/02/03/indonesian-twins-lin-back'n'1252877.html

Mayo Clinic (2012). Parkinson's disease. Retrieved from http:// www.mayoclinic.com/health/parkinsons-disease/DS00295

Paul, P. (2012, March 7). The joys of twins. In New York Times. Retrieved from http://www.nytimes.com/2012/03/07/books/ take-two-by-j-patrick-lewis-and-jane-yolen.html

Segal, N. L. (2000). Entwined lives: Twins and what they tell us about human behavior. New York: Plume.

Segal, N. L. (2009). Suicidal ideation and suicide attempts in surviving $\mathrm{MZ}$ and $\mathrm{DZ}$ co-twins. Suicide and LifeThreatening Behavior, 39, 569-575.

Segal, N. L. (2012). Comment on: Solvent exposure and Parkinson disease risk in twins. Annals of Neurology, DOI: 10.1002/ana.23624; see reply: DOI: 10.1002/ana.22629.

Tanner, C. M., Ottman, R., Goldman, S., Ellenberg, J., Chan, P., Mayeux, R., \& Langston, J. W. (1999). Parkinson disease in twins: An etiologic study. Journal of the American Medical Association, 281, 341-346.

Tarui, T., Khwaja, O. S, Estroff, J. A., Robinson, J. N., Gragas, M. C., \& Grant, P. E. (2012). Altered fetal cerebral and cerebellar development in twin-twin transfusion syndrome. American Journal of Neuroradiology. Advance online publication.

WebMD (2012). VACTERL Association. Retrieved from http://children.webmd.com/vacterl-association 